\title{
A Database Practicum for Teaching Database Administration and Software Development at Regis University
}

\author{
Robert T. Mason \\ Regis University, Denver, CO, USA
}

rmason@regis.edu

\section{Executive Summary}

This research paper compares a database practicum at the Regis University College for Professional Studies (CPS) with technology oriented practicums at other universities. Successful andragogy for technology courses can motivate students to develop a genuine interest in the subject, share their knowledge with peers and can inspire students to study the subject after they graduate from the university. One of the goals of the Regis database practicum is to inspire students to continue to study the subject of database technologies after they graduate (e.g., life long learning). A technology oriented practicum must provide students with the opportunity to develop both technological skills and soft skills (e.g., team work, effective communication, and work experience). The Regis database practicum fosters the development of soft skills by allowing students to volunteer in leadership roles, such as Project Manager, Technical Lead, and Project Lead. Students improve their communication skills by working on real-life software development projects with local stakeholders in the Denver area. Typical practicum team deliverables include functional requirements documentation, analysis and detailed design documentation, functional software, software test plans, status reporting of outstanding issues, and a final project report that summarizes the software development process that was followed during the practicum. The Regis database practicum also includes a database administration component in addition to a software development project. Students create and maintain the databases that are used for all of the undergraduate and graduate database courses within CPS for every 8 week term. Students also improve soft skills by working on the database support help desk on a weekly basis. Based on course evaluations, students have indicated that the Regis database practicum is a successful experience that helps them to fine tune their technical skills and to develop new soft skills.

Keywords: Active Learning, Practicum Experience, Database Administration, Database Application Development, Oracle APEX

\section{Introduction}

Material published as part of this publication, either on-line or in print, is copyrighted by the Informing Science Institute. Permission to make digital or paper copy of part or all of these works for personal or classroom use is granted without fee provided that the copies are not made or distributed for profit or commercial advantage AND that copies 1) bear this notice in full and 2) give the full citation on the first page. It is permissible to abstract these works so long as credit is given. To copy in all other cases or to republish or to post on a server or to redistribute to lists requires specific permission and payment of a fee. Contact Publisher@InformingScience.org to request redistribution permission.
A practicum experience gives students real-world experience and bridges the gap between theory and practice. A practicum experience can strengthen a student's confidence by increasing their knowledge base about the subject matter and reinforcing core competencies learned in prior course work (Hendrick $\&$ Hendrick, 2011). Practicums are not a new concept for andragogy (teaching 
methods for adult education). Student participation in a practicum that provides a cooperative learning experience is considered an essential component of many graduate education programs. Practicum training has been successfully applied in the areas of Education, Business Administration, Oncology, and Family Counseling (Atta, 2012; Hendrick \& Hendrick, 2011; Ratanasiripong \& Ghafoori, 2009; Spring Arbor University, 2011).

For example, a practicum is a core component of the teacher education program that allows student teachers to acquire beginning teaching competencies (Atta, 2012). The experience of a teaching practicum enables student teachers to practice the delivery of lessons without using rote memorization. Social life skills are enhanced via interaction with the students. When teaching computer science to high school students, a practicum experience allows the student teachers to meet with students to explain complicated topics (Hazzan \& Lapidot, 2004). The practicum also provides the opportunity for student teachers to practice their teaching skills via the delivery of a unit of instruction, assisting with computer lab work and tutoring students in small groups.

Another example of a practicum in the area of Business Administration includes a wide-range of practicum activities such as writing a business plan, managing a retail shop, creating computer record applications for non-profit organizations, coordinating a fund-raising campaign, and developing an inventory system (Spring Arbor University, 2012). Helfert (2008) describes a four month practicum that allows European students to analyze business problems and draw conclusions using scientific methods. Three examples of business information technology related practicum projects are:

- Investigation of Information Technology Support for detecting Money Laundering

- Review of the use of Service Oriented Architecture (SOA) in Supply Chain Management

- The effectiveness of Process Re-engineering in the Irish Health Care Industry

An example of a database practicum that is offered by Regis University (2013) is a viable and popular alternative to writing a thesis for two Master of Science (MS) degree programs: a Database Technology (DBT) program and a combined Software Engineering and Database Technology (SED) program. Students participate in the practicum for six months, complete two courses and earn six credit hours towards the completion of a 36 hour degree plan. Students are eligible to participate in the database practicum after they have completed the majority of their course work (30 credit hours).

A research objective for this paper is to investigate in more detail how the Regis University database practicum experience helps MS students develop both technical competence and soft skills. The concept of soft skills is described in the next section. The remainder of this paper will focus on practicums that are within Computer Information Sciences (CIS) disciplines and then will compare these programs to the Regis University database practicum.

\section{A Practicum for Software Development Project Management}

A practicum in the area of software development project management has unique properties because software development involves the transformation of intellectual ideas into a software product (Maqsood \& Javed, 2007). Students are required to integrate business domain knowledge, apply technical knowledge, and work with people from different organizational units within a company. Maqsood \& Javed (2007) suggest that students need a practicum environment that allows them to apply technical skills and develop soft skills (e.g., participation as a team player, use of management ethics and gain work experience in the corporate environment). To be effective software development project managers, students must learn how to: 
- Comprehend basic and best practices (e.g. SWEBOK - Software Engineering Body of Knowlege, PMBOK - Project Management Body of Knowledge) that are followed during development, deployment and retirement of software systems.

- Follow system development methodologies and apply the appropriate software development tools during the development process.

- Understand the importance of project documentation, quality assurance, requirements analysis, data integration and configuration management.

- Adhere to the software development requirements that are provided by the stakeholders.

Typical project management practicum team deliverables include the following items (Maqsood \& Javed, 2007):

- Functional requirements documentation

- Analysis and detailed design documentation

- Software test plans

- Status report of outstanding issues (bugs)

- A final project report that summarizes the software development process

Students are evaluated based on a variety of deliverables that include weekly status reports and meeting minutes, feedback from the project advisor and other team members, a project plan, comprehension of the domain issues, risk evaluation, project estimation, a quality assurance report, and a final project report.

In comparison, technical competence and soft skills are also important learning objectives for students studying database technologies at Regis University. The deliverables listed above are very similar to the Regis University database practicum project deliverables. In addition, Regis students follow a methodology that includes requirements gathering, analysis, design, coding, testing, and a final project report. Regis database practicum participants create project documentation at various stages throughout the development process.

\section{Hands-on Learning to Teach Database Technology}

A good example of teaching database technology to adult learners is provided by Moore, Binkerd and Fant (2002), who describe a Relational Database Management System (RDBMS) course at Texas A \& M University Corpus Christi (TAMU-CC) that uses hands-on learning. The RDBMS course provides students with four academic credit hours. Students participate in three hours of lecture per week and two hours of lab work. The lab work includes instruction on how to use web development tools with databases. Although the students are exposed to programming languages such as $\mathrm{C}++$ and assembly language in prior courses, this is the first class were students write code that interacts with a RDBMS.

The hands-on learning projects are based on applications that are needed by the university, therefore they can be considered service learning opportunities (Moore et al., 2002). For example, two recent projects included the development an art museum scheduling application and alumni registration application that interfaced with a RDBMS. The new alumni registration application captures demographic information about alumni (e.g., name, address, employer, major, and minor). The new art museum scheduling application allows web users to view schedules for exhibits, take virtual tours online and volunteer to conduct exhibit tours.

Ramakrishna (2000) also describes the importance of hands-on learning in the area of database technology andragogy. Ramakrishna noted that a majority of students (i.e., 87\%) preferred a 
learning model where they actively participated by using a RDBMS in comparison to the traditional model of lecture and technology demonstrations by the instructor. Ramakrishna suggests that successful andragogy will result in the following:

- Students will develop an interest in the subject.

- Students will be given an opportunity to communicate their knowledge with their peers.

- Students will be inspired to study the subject after they have graduated from the university.

Ramakrishna (2000) describes how he added weekly hands-on homework assignments to the curriculum to help students comprehend the subject matter. Students were asked to summarize the material, highlight important points from the lecture, and answer descriptive questions that required further reading of the assigned text. In addition, programming assignments were given to the students to reinforce the technical concepts and to help the students to improve their technical skills. Ramakrishna (2000) surveyed 45 students (28 responded) regarding the addition of homework assignments to the coursework. A large majority of the students (96\%) agreed (or strongly agreed) that the hands-on homework assignments helped them to understand the subject matter.

In comparison, database technology practicum students at Regis University are given the opportunity to perform a variety of technical tasks in the areas of Database Administration and Software Development. Students participate in additional training for Linux, Oracle Enterprise Manager (OEM), and Oracle Application Express (APEX). Students use Linux and OEM to create and maintain the Oracle databases for all of the 8 week database courses within the Regis University College for Professional Studies (CPS). Similar to the work that was described by Moore, Binkerd, and Fant (2002), the Regis students use Oracle APEX to develop web-based applications that benefit the university. Results from student follow-up surveys indicate that the additional technical training and hands-on experience within the database practicum is extremely beneficial.

\section{Hands-on Learning within a Database Practicum}

Meeker and Nohl (2007) emphasize the importance of hands-on learning as a supplement to passive learning when teaching database technology concepts to junior and senior undergraduate students. The database practicum course offered at Benedictine University (BU) provides students with exposure to additional perspectives that are not normally covered within the database systems course. The database practicum elective is one academic credit hour. Five different practicum experiences are offered to students and can be taken simultaneously with other computer science courses. Therefore, students have the option of taking additional practicum courses in the areas of Operating Systems, Computer Networks, Programming Theory and Numerical Analysis.

The BU database practicum consists of fourteen laboratory sessions that cover eleven independent projects (e.g. some projects span multiple weeks). Projects use different operating systems and DBMS, therefore the students are exposed to a broad spectrum of technology. For example, projects can include:

- Writing C\# programs to access a Microsoft Access Database

- Installing a Microsoft SQL Server database and then creating database constraints, triggers and views based upon a data model (ERD)

- Conversion of an application program for one particular RDBMS to another RDBMS

- Security for the SQL Server database and SQL Injection examples

- Creation of XML files that can be stored in a RDBMS 
Student reaction to the practicum experience was positive according to Meeker and Nohl (2007). Comments on an open-ended questionnaire indicated that the students thought the practicum offered a valuable experience because of the hands-on approach. The diversity of technology offered within the practicum appealed to the students. The additional technical work that the practicum required was not an issue for the students; in fact they seemed to enjoy it. The ability to "learn by doing", helped the students develop their problem-solving capabilities which in-turn boosted their confidence. Team work is encouraged in the practicum and students are able to reinforce their knowledge by discussing technical concepts with their peers.

In comparison, the Regis database practicum encourages the development of leadership skills and team work by allowing practicum participants to volunteer as project managers, team leads, and technical leads. Students are asked to peer review each other as a component of their final grade. Students rate each other based on the contribution to the work effort and the effectiveness of their communication skills. Providing leadership positions and problem solving opportunities are examples of the way that the Regis database practicum experience helps students to develop soft skills as described by Maqsood \& Javed (2007).

\section{Database Practicum at Regis University}

As mentioned previously, Regis University (2012) offers a database practicum as an alternative to writing a thesis for two Master of Science degree programs: a Database Technology (DBT) program and a combined Software Engineering and Database Technology (SED) program. While participating in the practicum, students create and maintain all the databases that needed for the database courses offered each 8 week term (Regis University, 2012). The student database administrators (DBAs) also provide help desk support for database related problems that arise during the six month time period. DBAs support the help desk for one week at a time and rotate the help desk responsibilities so that everyone on the team has multiple opportunities to support the help desk. Issues that cannot be easily resolved by the student DBAs are escalated to the practicum technical lead and the database faculty. After completing the first Practicum course ( 3 credit hours), students are able to perform the following tasks:

- Connect to the Linux operating system using the Putty software tool and then enter Linux commands to manage database related files on the Regis Academic Research Network (ARNe) servers based upon the Linux training received during the course.

- Install and upgrade Oracle Database Management software on the ARNe Regis database servers using Linux operating system commands and utilities (e.g., Oracle 11.0.2).

- Create new Oracle user IDs and manage security for Oracle users. Create tablespaces and allocate file space for the new tablespaces. Drop user IDs when they become obsolete.

- Create new Oracle databases for use by the Regis Database students and instructors for each 8 week term.

- Create documentation for students and instructors to access the XEN Citrix Environment on ARNe and then access the Oracle database(s). Maintain documentation for the DB practicum, including procedures followed by the practicum participants.

- Communicate via email with Regis instructors regarding the new databases and Oracle user IDs that are created each term. Provide instructors and students with detailed connection instructions that include screen shots. 
- Support Regis students and instructors via a help desk. Investigate and resolve any issues regarding the Oracle databases which can involve escalating critical issues to the DB Practicum technical lead and/or the DB faculty.

- Use Oracle Enterprise Manager (OEM) to monitor, evaluate, performance tune and administer Oracle databases based on the training received in this course.

- Monitor Regis ARNe server disk space usage and remove obsolete databases and data files.

- Develop web applications using Oracle Application Express (APEX) based upon the training received in this course.

Student DBAs are graded for the first DB Practicum course based on the following criteria (Regis University, 2012):

- $25 \%$ of the grade is based on the participation of the DBA in DB Practicum activities (e.g., attend weekly meetings, create and maintain databases, working on the help desk, solving technical problems that arise for students and faculty, etc.)

- $50 \%$ of the grade is based on the completion of the software training lab assignments for Oracle APEX, OEM and Linux for Oracle DBAs.

- $25 \%$ of the grade is based on a review by other practicum members regarding the DBA's contributions to the DB practicum and team work with the other DBAs.

During the second practicum course ( 3 credit hours), students participate in a real-life software development project that benefits an internal organization within Regis University (2012). After completing the second Practicum course ( 3 credit hours), students are able to perform the following tasks:

- Participate on a virtual software development team composed of people located at diverse geographical locations in the USA and Germany. They can make incremental contributions to the development of a high quality software application.

- Follow the DB Practicum software development methodology to analyze, design, code and test a web-based database software application on the Regis Academic Research Network (ARNe).

- Document, design and verify functional requirements, UML Use Cases, Sequence Diagrams, Entity Relational Diagrams (ERD) and Oracle Apex Web pages.

- Investigate and resolve challenging technical issues during the coding and testing phase of the software development project using the technical knowledge and expertise that was gained via earlier DBT course work.

- Create a new Oracle database to support the new Web-based software application. The database design will be based upon an ERD that is developed during the design phase of the software development lifecycle.

- Design and develop the Web-based portion of the application using Oracle Application Express (APEX).

- Document and adhere to software development standards for the new application.

- Develop and execute test plans to validate the new application. Debug and correct any application defects that are encountered during the test phase of the project. 
- Create a project report that details specific contributions to the software development process, how the software adheres to the functional requirements and how they leveraged the DB Practicum methodology.

Student DBAs are graded for the second DB Practicum course based on the following criteria (Regis University, 2012):

- $25 \%$ of the grade is based on the participation of the DBA in DB Practicum activities (e.g., attend weekly meetings, create and maintain databases, mentoring new DB practicum members, working on the help desk, solving technical problems that arise for students and faculty, etc.).

- $25 \%$ of the grade is based on the completion of the software development assignment, quality of their work and if the application supports the functional requirements and Use Case diagrams.

- $25 \%$ of the grade is based on instructor review of the Final DB Practicum Report.

- $25 \%$ of the grade is based on a review by other practicum members regarding the DBA's contributions to the DB practicum and team work with the other DBAs.

Deliverables from the Regis Database Practicum are similar to what was described by Maqsood and Javed (2007):

- Functional requirements documentation

- Analysis and detailed design documentation

- Software test plans

- A final project report that summarizes the software development process

\section{Discussion of the Regis University Database Practicum}

Although the Regis University (2012) Database Practicum has successfully operated for 14 years, it recently has been enhanced to offer students a hands-on learning experience in the two areas of Database Administration and Database Application Development. Students are provided with additional technical training during the first 8 week practicum course in the areas of Oracle Application Express, Oracle Enterprise Manager, and Linux for Oracle DBAs. The practicum ranges in size from 13 to 19 students. Weekly practicum meetings allow students and faculty to discuss help desk issues, examine technical problem resolutions, discuss the management of the database environment, participate in project planning and the review of project deliverables. Maqsood and Javed (2007) emphasized the importance of a practicum environment where students can develop soft skills (e.g., team work, effective communication, and work experience). Students that participate in the Regis University DB Practicum develop soft skills via project collaboration that requires written communication using email and verbal communication during the weekly meeting. As mentioned previously, throughout the six months, students volunteer as the project managers, team leads and technical leads, thus allowing them to develop and demonstrate group interaction skills.

One goal of the Regis University College of Professional Studies is to inspire students to make a commitment to learning as a lifelong endeavor (Regis University, 2012). A goal for the Database Technology program is for students to demonstrate the ability to maintain technological competence in the face of rapid changes in database technologies and the field of information technology during their careers. Ramakrishna (2000) discussed the importance of helping students develop an interest in the subject and then continue to study the subject once they have left the university. Regis CPS Alumni are periodically surveyed about their continuing education pursuits and career advancement. 
Therefore, the Regis database practicum strives to provide an academic environment that fosters the development of soft skills and life long learning. As part of the end of course survey that was taken in December 2012, students were asked "What course elements and/or facilitator practices contributed most to your learning?" The seven of the thirteen database practicum students that responded to the survey, replied as follows:

- The Hands-on assignments and the actual DBA type tasks.

- The labs were very relevant and I liked having other instructors cover their different sections - OEM, APEX, etc.

- Course Project

- Help desk experience and the development of the application

- Labs, Project tasks, and Final Report

- If this makes any sense, I really appreciated the "openness" of the program. Meaning that it is open to all levels of experience and yet still manages to offer something for everyone.

These comments are interesting because they indicate that students benefited from the variety of diverse tasks that comprise the database practicum curriculum. Meeker and Nohl (2007) describe the BU practicum options as a plethora of technical learning opportunities. The Regis database practicum is similar the BU practicum because it offers a variety of diverse technical challenges for students. Table 1 shows the results of the eleven statements that were presented as part of the database practicum course evaluation for the practicum that ended in December of 2012. Students were asked to rate each statement on a scale of 1 to 4 with 4 being the highest rating.

Table 1. Results from Database Practicum course evaluation in December 2012.

\begin{tabular}{|l||c|c||c||c||}
\hline \multicolumn{1}{||}{ Questions } & \multicolumn{3}{c||}{ Statistics } \\
\cline { 2 - 5 } & Mean & Med. & Mode & S.D. \\
\hline \hline $\begin{array}{l}\text { Course objectives were stated } \\
\text { clearly. }\end{array}$ & 3.9 & 4 & 4 & .35 \\
\hline \hline $\begin{array}{l}\text { Course provided opportunities to } \\
\text { practice ethical problem solving and } \\
\text { decision making. }\end{array}$ & 3.6 & 4 & 4 & .49 \\
\hline $\begin{array}{l}\text { Course expanded my knowledge of } \\
\text { the course subject matter. }\end{array}$ & 3.7 & 4 & 4 & .45 \\
\hline $\begin{array}{l}\text { Course activities helped me to un- } \\
\text { derstand the course learning objec- } \\
\text { tives. }\end{array}$ & 3.7 & 4 & 4 & .45 \\
\hline \hline Course challenged me intellectually. & 3.9 & 4 & 4 & .35 \\
\hline $\begin{array}{l}\text { Course assessments gave me a } \\
\text { chance to demonstrate my learning. }\end{array}$ & 3.5 & 4 & 4 & .76 \\
\hline $\begin{array}{l}\text { Course was relevant to my profes- } \\
\text { sional goals. }\end{array}$ & 4 & 4 & 4 & 0 \\
\hline \hline $\begin{array}{l}\text { Course helped me to be more effec- } \\
\text { tive at what I value. }\end{array}$ & 3.6 & 4 & 4 & .49 \\
\hline \hline $\begin{array}{l}\text { I consistently read the assigned } \\
\text { readings. }\end{array}$ & 3.5 & 3.5 & 3.4 & .50 \\
\hline \hline $\begin{array}{l}\text { I asked questions in class or con- } \\
\text { tributed to class discussions. }\end{array}$ & 3.9 & 4 & 4 & .35 \\
\hline \hline I would recommend this course. & 3.9 & 4 & 4 & .35 \\
\hline \hline
\end{tabular}


Comments from the practicum participants were positive. Four encouraging comments are listed below:

"Overall, the project proved to be an excellent introduction to web application design and implementation, along with an excellent vehicle to, once more, test my Oracle database knowledge and application (development) skills."

"The project taught me a lot about the process of business analysis, gathering user requirements, designing use cases, design of a relational database and implementing a service-oriented architecture. I thought the project would be difficult, given the short time frame, but after regular meetings with the (stakeholders) staff, I gained a fuller understanding of how the existing system worked, and what new system features were going to be implemented. After repeated work efforts, the design began to take shape and the project seemed to take on a life of its own."

"I have really enjoyed working with the Practicum team and especially stakeholders as we coordinated with the manager and her team to understand what they needed in future software. This has been an experience that would not have been possible if I had written a Thesis instead. The simple method of starting from ground zero and having to put it all together has been a tremendous learning experience. Everyone involved has been helpful in providing the team with the information needed."

"Overall I believe that the goal of the practicum has been accomplished. I experienced many of the same issues participating on the team as I do on current software development projects or performing database administration tasks... While we are not too far behind our original timeline, as we begin testing, we may discover that there was some miscommunication among the developers concerning the requirements. This is natural and a normal experience for software development, and I believe a successful implementation of the goals of the practicum (was achieved)."

These comments from students indicate that the Regis database practicum is meeting the goals of enhancing technical skills and soft skills (human interaction and communication skills) as described by Maqsood and Javed (2007). Practicum students gained a better understanding of the software development life cycle and the issues that plague the software industry in regards to project management timelines and working with stakeholders.

\section{Conclusion}

Hands-on learning via a practicum experience is common place in many graduate education programs. In the area of software development, a practicum involves the transformation of intellectual ideas into a software product. A technology oriented practicum must provide both technological skills and soft skills. The Regis University Database Practicum includes both a Database Administration component and a Software Development component. Based on course evaluations, students have indicated that the Regis database practicum is a successful experience that helps them to fine tune their technical skills and to develop new soft skills.

\section{References}

Atta, N. (2012). Improving teaching practicum by relating learning with practical life skills: An action research. International Journal of Social Sciences and Education, 2(1), 500.

Hazzan, O., \& Lapidot, T. (2004). The practicum in computer science education: Bridging gaps between theoretical knowledge and actual performance. The SIGCSE Bulletin, 36(4), 47-51. 
Helfert, M. (2008). Business informatics: An engineering perspective on information systems. Journal of Information Technology Education, 7, 223-245. Retrieved from http://www.jite.org/documents/Vol7/JITEv7p223-245Helfert354.pdf

Hendrick, S. S., \& Hendrick, C. (2011). Creating an oncology practicum: A partnering approach. Training and Education in Professional Psychology, 5(4), 229-236. doi: 10.1037/a0026229

Maqsood, M. E., \& Javed, T. (2007). Practicum in software project management: An endeavor to effective and pragmatic software project management education. Paper presented at ESEC/FSE.

Meeker, R., \& Nohl, D. (2007). Using a practicum experience in your database course. Journal of Computing Sciences in Colleges, 23(1), 91-96.

Moore, M., Binkerd, C., \& Fant, S. (2002). Teaching web-based database application development: An inexpensive approach. Paper presented at CCSC: Central Plains Conference.

Ramakrishna, M. V. (2000). A learning by doing model for teaching advanced databases. ACSE '00 Proceedings of the Australasian Conference on Computing Education, pp. 203-207

Ratanasiripong, P., \& Ghafoori, B. (2009). Setting up the on-site marriage and family therapy clinical training course. Journal of Instructional Psychology, 36(4), 347-351.

Regis University. (2013). Master's of science database practicum. Website. Abstract retrieved, 2012, from http://academic.regis.edu/dduncan/center_DB_Research_Main.html

Spring Arbor University. (2012). Website. Abstract retrieved, 2012, from http://online.arbor.edu/landing/programs.php

\section{Biography}

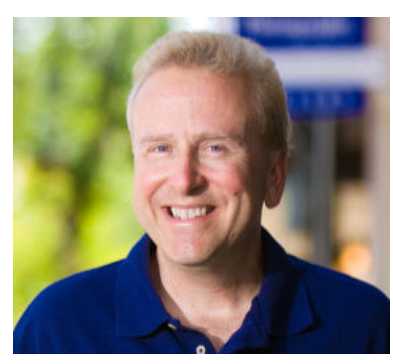

Robert (Bob) Mason joined the Regis University College for Professional Studies (CPS) as an Assistant Professor in January, 2011. He is the program coordinator for the CPS SCIS Database Technologies program. Prior to joining Regis as a full-time faculty member, he was an affiliate faculty member at Regis University for 10 years. In addition to teaching, Bob was employed by various Fortune 500 companies for 25 years as a Data Architect, DBA and Software Engineer.

Bob completed his Ph.D. in Computer Information Systems (CIS) at Nova Southeastern University. As part of his research, he designed and built a SOA Middleware prototype that was based on the 28 functional requirements that were provided by the panel of seven CIS experts. This prototype helps to resolve the interoperability gap challenges that exist between Learning Object Repositories \& Learning Management Systems. He has a MBA with an emphasis in CIS from the University of North Texas. Bob has an undergraduate degree in Forestry Management and Business from the University of Tennessee. You can email Bob Mason at rmason@regis.edu. 